\title{
ORIGINAL
}

Pawel Romanowicz

\section{Numerical assessment of fatigue load capacity of cylindrical crane wheel using multiaxial high-cycle fatigue criteria}

Received: 16 July 2016 / Accepted: 14 July 2017 / Published online: 27 July 2017

(C) The Author(s) 2017. This article is an open access publication

\begin{abstract}
The application of multiaxial high-cycle fatigue criteria to the analysis of the subsurface rolling contact fatigue of structures working in contact conditions is discussed. In such objects, an increase in compressive and shear stresses is strongly non-proportional. Therefore, the first part of the paper is devoted to the comparison of the results of six recently used high-cycle fatigue criteria estimating the effort for both different multiaxial proportional and non-proportional loads. In the second part of the paper, the issue of frictionless and tractive rolling contact fatigue is discussed. The fatigue load capacity of a crane wheel has been estimated using recently popular criteria. The orientation of critical planes and location of dangerous points are determined and discussed in detail. It has been found that the Dang Van criterion, which is often proposed in rolling contact fatigue analysis, underestimates the equivalent fatigue stress for such type of loads. Comparison of the results obtained using different multiaxial criteria with the results of the experimental tests enables a selection of criteria suitable for fatigue assessment of machine parts working in cycling rolling contact conditions.
\end{abstract}

Keywords Multiaxial high-cycle fatigue $\cdot$ Non-proportional loading $\cdot$ Numerical simulation $\cdot$ Rolling contact fatigue (RCF)

\section{List of symbols}

$a$
$a_{\mathrm{C}}, a_{\mathrm{DV}}, a_{\mathrm{P}_{2}}$
$D_{\mathrm{w}}, R_{\mathrm{w}}$
$E$
$F$
$f_{-1}$
$F_{\mathrm{Rd}, \mathrm{f}}$
$F_{u}$
$k$
$M$
$\mathrm{MHCF}$
$N$
$N_{\mathrm{f}}$
$\mathrm{P}-\mathrm{L}$
$p_{o}$
$Q_{\mathrm{n}}$

Semiaxis of the contact ellipse in the direction of rolling

Constants of MHCF criteria

Diameter and radii of the wheel, respectively

Young modulus

Normal force

Alternate bending fatigue strength

Limit design contact force

Minimum contact force

Material coefficient in energy criterion

Torque moment

Multiaxial high-cycle fatigue

Number of hoisting cycles

Number of cycles to failure

Palmgren-Lundberg

Maximal contact pressure

Nominal load

P. Romanowicz $(\square)$

Institute of Machine Design, Cracow University of Technology, ul. Warszawska 24, 31-155 Cracow, Poland

E-mail: promek@mech.pk.edu.pl 


$r$
RCF
$R_{k}$
$t$
$t_{-1}$
$<T_{\mathrm{a}}>$
$T_{\mathrm{a}}(\varphi, \theta)$
$W_{a f}$
$W_{\mathrm{n}}$
$W_{\mathrm{ns}}$
$x_{z}$
$\beta$
$\delta$
$\delta_{\Delta}$
$\Delta=\Delta(\varphi, \theta)$
$\varepsilon$
$\theta_{r \phi}$
$\mu$
$\nu$
$\sigma_{1}, \sigma_{2}, \sigma_{3}$
$\sigma_{\mathrm{I}}, \sigma_{\mathrm{II}}, \sigma_{\mathrm{III}}$
$\sigma_{H}$
$\sigma_{\mathrm{y}}$
$\sigma_{u}$
$\sigma_{\mathrm{vM}, \mathrm{a}}$
$\sigma_{\mathrm{H}, \max }$
$\tau$
$\tau_{\mathrm{eqv}}=\left\{\tau_{\mathrm{C}}, \tau_{\mathrm{DV}}, \tau_{\mathrm{DVmod}}\right.$,
$\left.\tau_{\mathrm{DV} 2 \mathrm{mod}}, \tau_{\mathrm{P}}, \tau_{\mathrm{P}}, \tau_{\mathrm{E}}\right\}$
$\tau_{\mathrm{ns}}$
$\chi$
${ }_{\mathrm{H}}$

\section{Subscripts}

Radius

Rolling contact fatigue

Railhead radius

Time

Alternate torsion fatigue strength

Resolved shear stress amplitude

Generalized shear stress amplitude

Limit of strain energy density parameter

Normal strain energy density parameter

Strain energy density parameter

Safety factor

Material coefficient in energy criterion

Shift in-phase between normal and tangent stresses

Step in numerical calculations

Material plane with orientation defined by two angles: $\varphi$ and $\theta$; angle $\chi$ defines direction of versor $s$ in plane $\Delta$

Strain

Angular location of material plane in relation to local coordinate system $r-\phi$.

Friction coefficient

Poisson's ratio

Principal stresses

Algebraically ordered principal stresses

Hydrostatic stress

Yield limit

Tensile strength

Amplitude of the second stress invariant

Maximal value of hydrostatic stress

Macroscopic shear stress

Equivalent fatigue stress

Shear stress on plane $\Delta$

Direction of the scalar value of the resolved shear stress $\tau=\boldsymbol{n} \cdot \boldsymbol{\sigma} \cdot \boldsymbol{s}$ on plane $\Delta$,

$\begin{array}{ll}\text { a } & \text { Amplitude } \\ \mathrm{eqv} & \text { Equivalent } \\ \mathrm{m} & \text { Mean value } \\ \mathrm{t} & \text { Time } \\ \mathrm{C} & \text { Crossland criterion } \\ \mathrm{DV} & \text { Dang Van criterion } \\ \mathrm{DV} \text { mod } & \text { Modified Dang Van criterion } \\ \mathrm{E} & \text { Lagoda criterion } \\ \max & \text { Maximum } \\ \mathrm{P}_{1} & \text { Papadopoulos criterion based on the integral formulation } \\ \mathrm{P}_{2} & \text { Papadopoulos criterion based on the critical plane approach } \\ \mathrm{PL} & \text { Palmgren-Lundberg points } \\ \mathrm{TG} & \text { Tresca-Guest } \\ x, y, z & \text { Geometric coordinates }\end{array}$

\section{Introduction}

Machine elements and mechanisms are often exposed to variable loading conditions (cyclic, random) which induce variable fatigue stresses and deformations. In consequence, when a certain level of fatigue effort and a certain number of equivalent cycles (corresponding to the threshold of respective fatigue endurance) are 

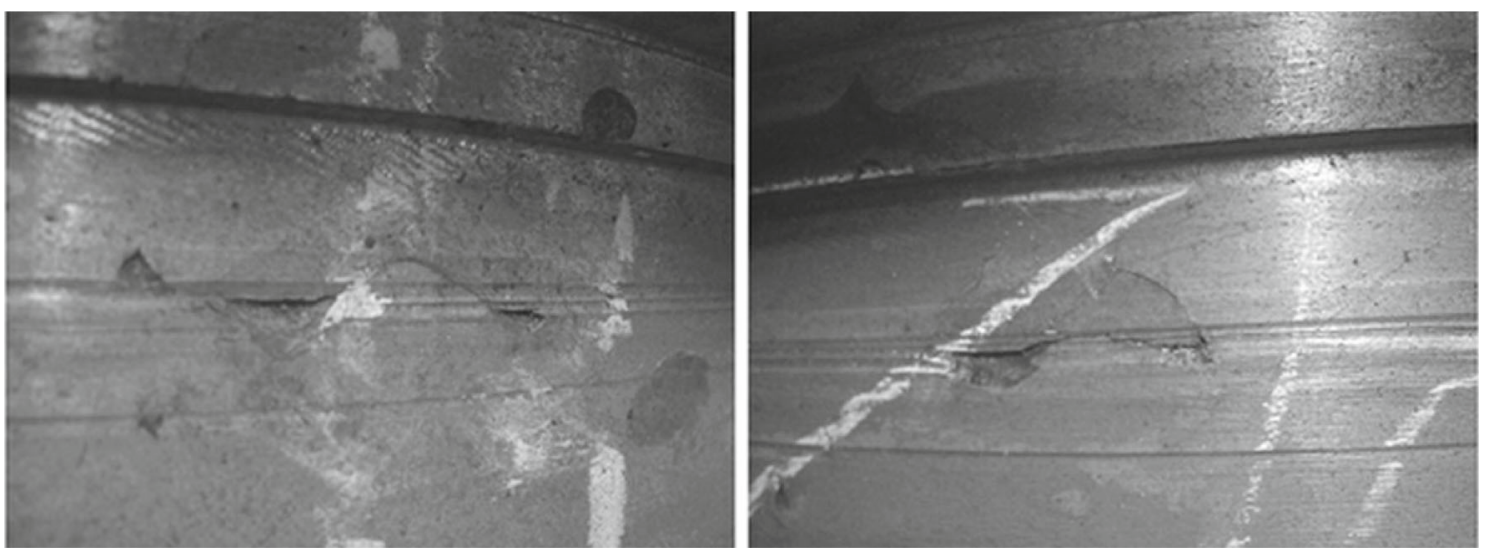

Fig. 1 Surface cracks on crane wheel tread surface

exceeded, fatigue failure may follow. Crane wheels are elements subjected to fatigue damage. Fatigue cracks (Fig. 1) are initiated beneath the surface and on reaching a certain size, they propagate fast. This dangerous phenomenon considerably decreases safety and durability of the structure. The fatigue of both free (frictionless) and tractive rolling contact of a typical cylindrical crane wheel $\phi 710$ made of $30 \mathrm{CrNiMo} 8$ with rail A120 [1] are investigated. The rail A120 (with railhead radius $R_{k}=600 \mathrm{~mm}$ ), which is used in the analysis, is recommended for the investigated cylindrical crane wheel. The fatigue analyses are made using the multiaxial high-cycle fatigue (MHCF) hypotheses which were recently investigated in [2,3]. Such MHCF criteria are described in Sect. 3 of the paper.

In the case of a complex stress state different MHCF hypotheses are used [4]. Such criteria allow for estimation of equivalent fatigue stress for complex or multiaxial loadings.

The various theories which have been proposed so far:

- existence of a critical or damage plane in which fatigue failure is caused by stresses $[5,6]$,

- based on deformation or stress invariants [7],

- energy formulations [8],

- integral approach [9],

- generalized extensions of empirical results [4],

have much smaller areas of application than the criteria of static endurance. Most of the hypotheses are limited to certain loading conditions or particular materials. Therefore, if there is no certainty which hypothesis will provide proper estimation, it is reasonable to apply a few popular criteria (e.g. [5-9]) and to compare obtained results.

The MHCF hypotheses presented in the paper have been selected for application to a rolling contact fatigue problem (RCF). This problem is especially important in the analysis of elements working in contact conditions, as for example, railway wheels and rails, gears, ball and roller bearings and cams. RCF is an example of a phenomenon in which a complex and multiaxial stress state (three normal compressive and three shear stresses may occur) with components changing non-proportionally appears. An in-phase shift between tangent and normal stresses is in the RCF particularly significant and large compressive effects in places of potential initiation of fatigue cracks complicate the situation.

Generally for rolling contact problems, three contact failure mechanisms can be distinguished (using an example of a railway wheel) [10]:

1. Surface cracks initiated by surface plasticity (ratchetting) caused by contact stresses. Crack growth process can be promoted by other causes - corrosion, insufficient lubrication, surface defects and asperities or thermal loads. This type of failure affects components subjected to cycling loading with high friction components such as curving, braking, traction.

2. Subsurface fatigue (load cases with moderate surface friction $\mu \leq 0.3$ ) that is initiated a few millimetres (typically $4 \div 5$ millimetres) below the surface. The location of subsurface crack origination can change due to material hardening, residual stresses or material defects.

3. Deep defect initiated fatigue- these forms of cracks can propagate in the area of low stresses (to $20 \mathrm{~mm}$ below the surface). 
The subsurface cracks are the most dangerous form of fatigue failure. Such problem (subsurface fatigue) is often investigated by applying MHCF hypotheses such as proposed by Crossland [11-13], Dang Van, Papadopoulos [11], Liu-Mahadevan [14-16], Liu-Zenner (this model requires four fatigue limits) [17]. The Dang Van model has been frequently used in RCF analysis of railway wheels and rails [5,18-22], rolling bearings [23,24] and other mechanical parts working in RCF loading condition [25]. However, significant critical remarks about the application of this criterion to RCF can be found in certain papers [11,17,26-28].

The fatigue criteria used in the study done by the author of the present paper are based on different approaches. The oldest one uses stress tensor invariants [7]. The Crossland criterion is a certain modification of the Sines formula [4], in which the mean value of the first invariant is replaced by its maximal value. The Crossland modification makes the model more compatible with experimental tests. The other considered hypotheses [5,6] are based on the critical plane assumption, or the use of the mean values of stresses [9]. The last one, but not the least important, is the energy formulation $[8,29]$ in which different combinations of energy-type fatigue effort estimators were proposed.

The high number of the MHCF criteria makes selection of a suitable hypothesis difficult. Moreover, the results obtained using different criteria show significant differences $[2,3]$. The application of an inadequate criterion may result in fatigue failure during operation. For this reason, one of the most important aims of the paper is to compare the most popular criteria and select of the most appropriate criterion for the rolling contact fatigue problems. The other main aims are to identify the critical points at which cracking may initiate and determine the critical loading for the investigated crane wheel.

In Sect. 2 of the paper, the problem of free and tractive rolling contact is discussed. The determination of the critical planes and points at which fatigue cracks may occur is illustrated by the case of a cylindrical crane wheel $\phi 710$. In Sect. 3 the MHCF criteria, which are the most often used in the RCF analyses are described. The detailed procedure of the criteria programming algorithms can be found in [30]. In Sect. 4 a comparative analysis for all the above hypotheses is performed for basic loading cases showing the scale of discrepancies between them. In Sect. 5, the numerical FEM analyses of the crane wheel $\phi 710$ made of $30 \mathrm{CrNiMo} 8$ are presented. The analyses are made for two cases - free and tractive rolling contact. In Sect. 6, the application of the MHCF criteria for the analysis of the crane wheel is shown and the obtained results are discussed. Conclusions are given in the final paragraph.

\section{Free and tractive rolling contact phenomena}

The rolling contact fatigue is an example of the phenomenon in which complex state with non-proportional stresses appears (Fig. 2). In-phase shift between normal and tangent stresses (see. Fig. 2) is particularly important in this case. Additionally, large compressive effects in places of potential initiation of fatigue cracks have a strong influence.

In free rolling, friction effects are negligibly small and can be omitted during analysis. This problem can be approximately solved using the Hertz theory. However, the use of the finite element method (FEM) can take into account complex geometry of the investigated structure. Using this method, it is also possible to include some additional factors such as surface roughness and material nonlinearity, which are disregarded in the simplified analytical methods [30]. Furthermore, the problem of tractive rolling contact requires including strong friction effects [31].

The amplitudes of stresses play a main role in the process of fatigue failure. Therefore, three characteristic points can be distinguished in the case of free rolling contact. One of them is the Bielajev point, in which, under the wheel tread surface the equivalent stresses (Tresca-Guest or von Mises $\sigma_{\mathrm{vM}}$ ) are the largest. The other Palmgren-Lundberg (P-L) points seem to be the most dangerous in the case of free rolling. It is justified by the fact that on the radius of $\mathrm{P}-\mathrm{L}$ points the amplitude of shear stress $\tau_{y z}$ is the largest.

The time function can be considered as parametric rotation of the wheel $\phi$ (Fig. 3) and the stresses distribution on a chosen radius can be used in the fatigue calculations. In Fig. 3 characteristic orientations of particles (for maximal shear stress in the Bielajev point and the maximal shear stresses in both P-L points) are indicated. The angle $\theta_{r \phi}$ means angular location of the investigated material plane in relation to the $r-\phi$ local coordinate system.

As it was mentioned in introduction and discussed above the crack initiate a few millimetres below the surface of two compressed bodies. In such situation, the influence of out-of-phase loading on the fatigue strength is probably similar to the material behaviour during the experimental tests of un-notched samples [32]. There is also three dimensional pulsating compression, which should have rather a positive effect on the 

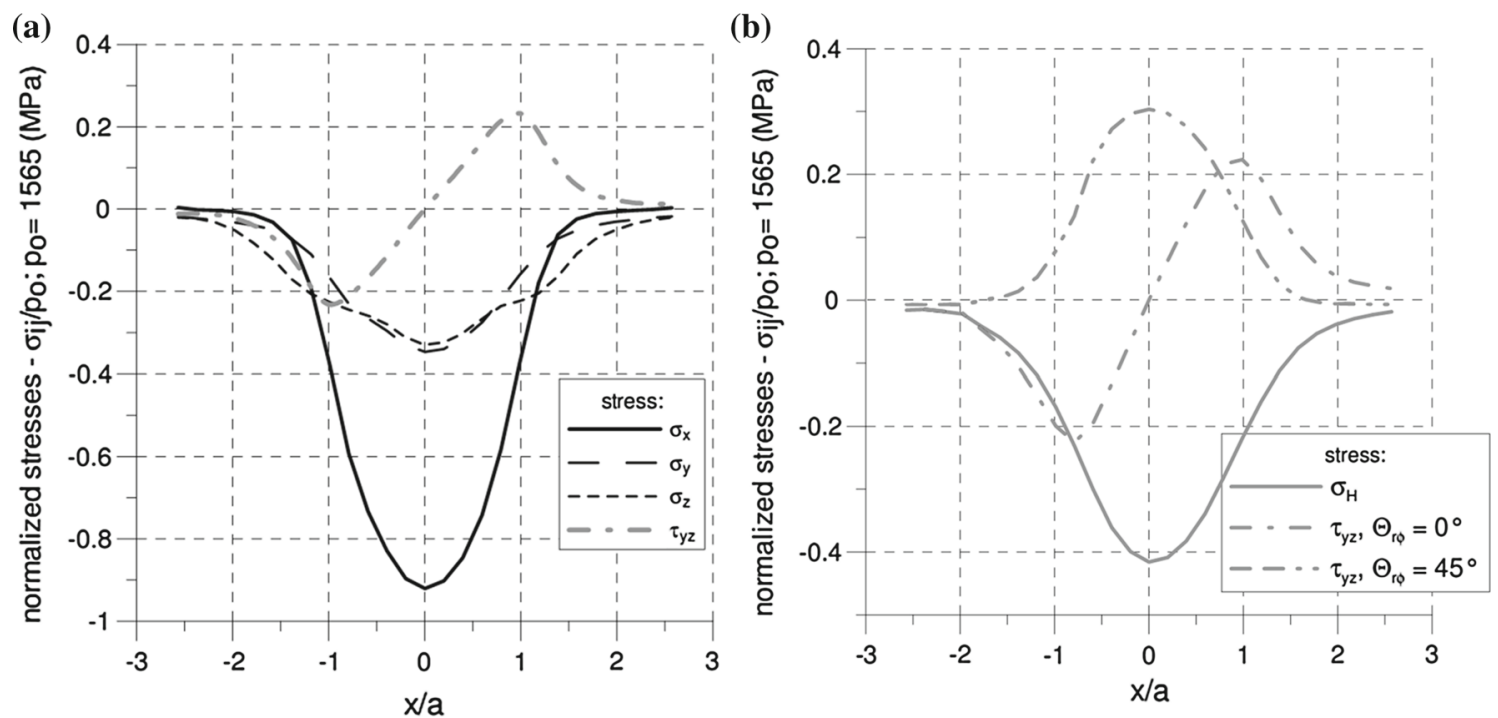

Fig. 2 Subsurface stress distribution for the investigated crane wheel: a on radius of Palmgren-Lundberg points, load $F=$ $294,3 \mathrm{kN}$, b hydrostatic $\sigma_{\mathrm{H}}$ and shear stress $\tau_{r \Phi}$ (for $\theta_{r \Phi}=0^{\circ}$ ) and $\tau_{r \Phi}$ (for $\theta_{r \Phi}=45^{\circ}$ ) distributions on radius $r_{\mathrm{B}}$ of Bielayev point, $a$-semiaxis of contact ellipse

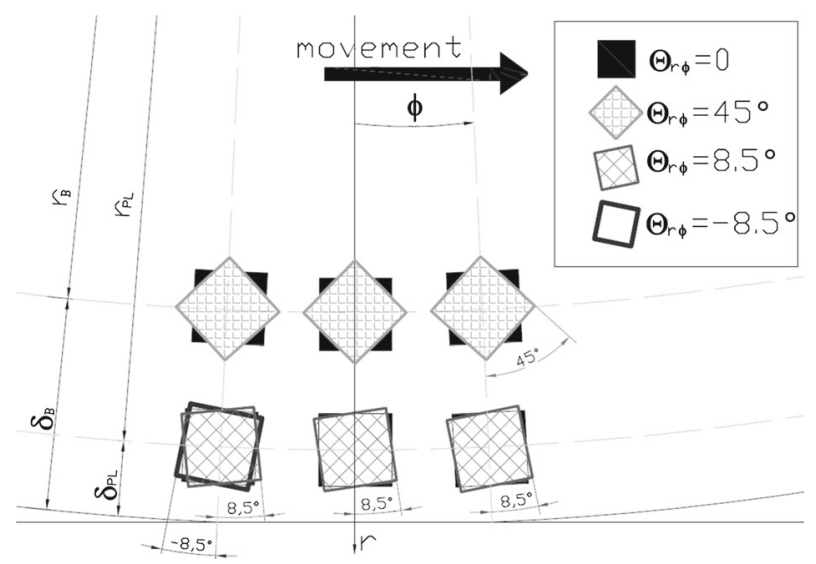

Fig. 3 The $r-\Phi$ local coordinate system and methodology of determination of stresses in the function of time in corresponding material planes. Angle $\theta_{r \Phi}$ denotes angular location of investigated material plane in relation to local coordinate system $r-\Phi$

fatigue (Fig. 2a). It can be observed that the subsurface stress state in rolling contact differs from the above in test samples. In the author's opinion, this loading case should be analysed in a separate experimental fatigue study.

Characteristic anti-symmetrical distribution of shear stress for points on $r_{\mathrm{PL}}$ radius and $\theta_{r \phi}=0$ is presented in Fig. 2a. It can be observed that the shear stress on $r_{\mathrm{PL}}$ radius is a shift in phase relative to hydrostatic stress. It should be noted that the maximal shear stresses in P-L points occur for different $\theta_{r \phi}=\left\{8.5^{\circ} ;-8.5^{\circ}\right\}$ (Figs. 3, 4). However, for both orientations $\left(\theta_{r \phi}\right)$ the amplitude of shear stress is reduced in relation to $\theta_{r \phi}=0^{\circ}$. So it seems to be reasonable to define the critical plane for angle $\theta_{r \phi}=0^{\circ}$.

The second interpretation of DV criterion requires calculation of Tresca-Guest shear stress $\tau_{\mathrm{TG}}$. An example of distribution of this stress on $r_{\mathrm{PL}}$ and $r_{\mathrm{B}}$ radii with planes rotation for maximal values for a $2 \mathrm{D}$ cylinder flat plane contact is presented in Fig. 4. It can be observed that the maximal shear stress in the vicinity of P-L points is almost the same on both $r_{\mathrm{PL}}$ and $r_{\mathrm{B}}$ radii, but for $\phi=0$ the difference is noticeable. However, slight changes of shear stress in the vicinity of $\mathrm{P}-\mathrm{L}$ points are accompanied by a considerable reduction of hydrostatic stress, which is unfavourable to the fatigue life in the sense of DV hypothesis. Maximal hydrostatic stress on different radii occurs for $\phi=0$. 


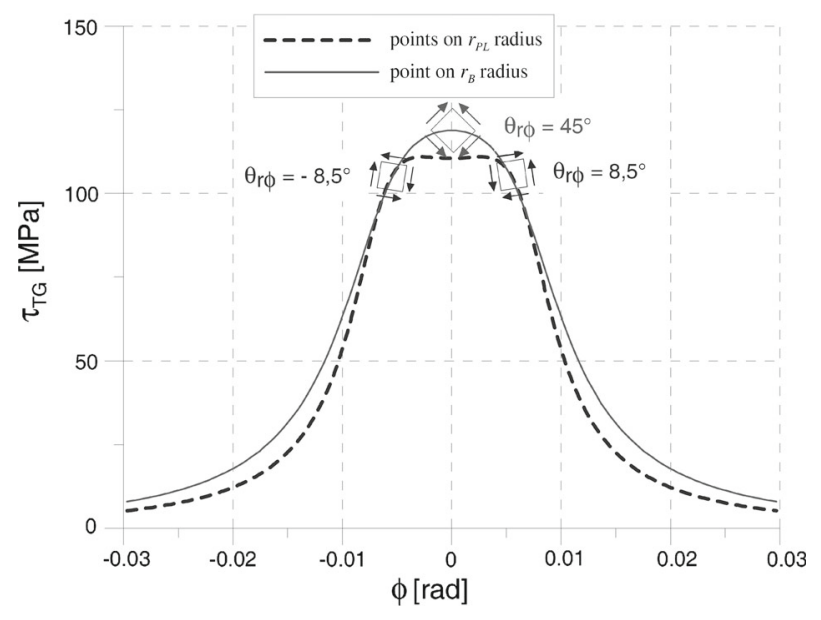

Fig. 4 The maximal shear stress in points on $r_{\mathrm{PL}}$ and $r_{\mathrm{B}}$ radii $\left(\theta_{r \Phi}\right.$ is various)

As already mentioned, the maximal von Mises stress $\sigma_{\mathrm{vMmax}}$ occurs below the tread surface in the Bielajew point for $\theta_{r \phi}=45^{\circ}$. During rolling the amplitude of shear stress in this point is smaller than the amplitude on $r_{\mathrm{PL}}$ radius (Fig. 2). Consequently, the maximal shear stress amplitude is closer to the surface and occurs in the Palmgren-Lundberg points. The region of these points (their radius $r_{\mathrm{PL}}$ ) proved to be the most dangerous. A more thorough analysis of this phenomenon can be found in [30].

The problem of subsurface crack initiation has often been investigated using the different multiaxial highcycle fatigue hypotheses $[6,7,9,11,14,17,26,33]$. These criteria are based on different approaches (see Sec. 3). The characteristic difference between them is the approach to the impact of phase shift on fatigue life. The criteria based on the integral approach (e.g. $\mathrm{P}_{1}$ ) neglect this effect on fatigue strength. The hypotheses based on the critical plane theory assume that $90^{\circ}$ phase shift increases fatigue life of a loaded component. This fact is important in the rolling contact fatigue, because the subsurface stresses are complex. Six components of the stress tensor may appear and the shear stress is out-of-phase in relation to the negative normal stresses. Hence, the principal stresses change their directions during each cycle.

\section{Multiaxial high-cycle fatigue criteria}

\subsection{Crossland criterion (C)}

In his criterion Crossland assumes [7], in the local measure of fatigue effort, a linear relationship between the admissible amplitude of the second stress invariant $\left(\sigma_{\mathrm{vM}, \mathrm{a}}\right)$ and the maximal value of hydrostatic stress $\sigma_{\mathrm{H}, \max }$ (first stress invariant):

$$
\tau_{\mathrm{C}}=\sigma_{\mathrm{vM}, \mathrm{a}} / \sqrt{3}+a_{\mathrm{C}} \cdot \sigma_{\mathrm{H}, \max } \leq t_{-1}
$$

where

$$
\begin{aligned}
a_{\mathrm{C}} & = \begin{cases}0 & \text { for } 3 t_{-1} / f_{-1} \leq \sqrt{3} \\
\left(\frac{3 t_{-1}}{f_{-1}}-\sqrt{3}\right) & \text { for } 3 t_{-1} / f_{-1}>\sqrt{3}\end{cases} \\
\sigma_{\mathrm{H}, \max } & =\max _{t} \sigma_{\mathrm{H}}(t)=\max _{t}\left\{\left[\sigma_{1}(t)+\sigma_{2}(t)+\sigma_{3}(t)\right] / 3\right\}
\end{aligned}
$$

$f_{-1}, t_{-1}$ are alternating bending and torsion fatigue limits, respectively.

The amplitude of the second stress invariant for arbitrary, non-proportional loading, as in rolling contact problems, $\sigma_{\mathrm{vM}, \mathrm{a}}$ can be calculated from the formula:

$$
\begin{aligned}
& \sigma_{\mathrm{vM}, \mathrm{a}}= \\
& \max _{t}\left[\frac{1}{\sqrt{2}} \sqrt{\left(\sigma_{x, \mathrm{a}}^{t}-\sigma_{y, \mathrm{a}}^{t}\right)^{2}+\left(\sigma_{y, \mathrm{a}}^{t}-\sigma_{z, \mathrm{a}}^{t}\right)^{2}+\left(\sigma_{z, \mathrm{a}}^{t}-\sigma_{x, \mathrm{a}}^{t}\right)^{2}+6\left[\left(\tau_{x y, \mathrm{a}}^{t}\right)^{2}+\left(\tau_{y z, \mathrm{a}}^{t}\right)^{2}+\left(\tau_{z x, \mathrm{a}}^{t}\right)^{2}\right]}\right]
\end{aligned}
$$


where $\sigma_{x, \mathrm{a}}^{t} ; \sigma_{y, \mathrm{a}}^{t} ; \ldots ; \tau_{z x, \mathrm{a}}^{t}-$ amplitude function of stresses, varying in time:

$$
\sigma_{x, \mathrm{a}}^{t}=\sigma_{x}(t)-\sigma_{x, \mathrm{~m}}
$$

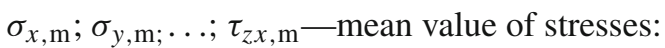

$$
\sigma_{x, \mathrm{~m}}=\frac{\max _{t}\left\{\sigma_{x}(t)\right\}+\min _{t}\left\{\sigma_{x}(t)\right\}}{2}
$$

For any proportional load the amplitude (4) is:

$$
\sigma_{\mathrm{vM}, \mathrm{a}}=\frac{1}{\sqrt{2}} \sqrt{\left(\sigma_{x, \mathrm{a}}-\sigma_{y, \mathrm{a}}\right)^{2}+\left(\sigma_{y, \mathrm{a}}-\sigma_{z, \mathrm{a}}\right)^{2}+\left(\sigma_{z, \mathrm{a}}-\sigma_{x, \mathrm{a}}\right)^{2}+6\left(\tau_{x y, \mathrm{a}}^{2}+\tau_{y z, \mathrm{a}}^{2}+\tau_{z x, \mathrm{a}}^{2}\right)}
$$

and

$$
\sigma_{\mathrm{H}, \max }=\max _{t} \sigma_{\mathrm{H}}(t)=\sigma_{\mathrm{H}, \mathrm{m}}+\sigma_{\mathrm{H}, \mathrm{a}}
$$

where $\sigma_{\mathrm{H}, \mathrm{m}}$ and $\sigma_{\mathrm{H}, \mathrm{a}}$ are the first stress invariants for the steady and amplitudal stress states, respectively.

\subsection{Dang Van's criteria (DV)}

\subsubsection{1 criterion}

The basic Dang Van model (DV) [5,33] requires determination of a critical plane in which equivalent DV fatigue stress achieves maximal value. The original DV formula (9) takes into account macroscopic shear $\tau(t)$ and hydrostatic $\sigma_{\mathrm{H}}(t)$ stresses). It is assumed that fatigue failure occur when the equivalent DV stress $\tau_{\mathrm{DV}}(9)$ goes beyond the admissible area, which is determined by inequality:

$$
\tau_{\mathrm{DV}}^{\mathrm{MAX}}=\max _{t}\left[\tau(t)+a_{\mathrm{DV}} \cdot \sigma_{\mathrm{H}}(t)\right] \leq t_{-1}
$$

where:

$$
\begin{aligned}
& \tau(t) \text {-fatigue shear stress } \\
& \sigma_{\mathrm{H}}(t)=\frac{1}{3}\left(\sigma_{1}(t)+\sigma_{2}(t)+\sigma_{3}(t)\right) \\
& \sigma_{1}, \sigma_{2}, \sigma_{3} \text {-principal stresses } \\
& a_{\mathrm{DV}}=\left\{\begin{array}{lll}
0 & \text { for } & \frac{3 t_{-1}}{f_{-1}} \leq 1.5 \\
\left(\frac{3 t_{-1}}{f_{-1}}-1.5\right) & \text { for } & \frac{3 t_{-1}}{f_{-1}}>1.5
\end{array} .\right.
\end{aligned}
$$

The main idea of this hypothesis is that cracks are initiated inside material grains. It may happen when the sum of external shear stress and internal residual stresses, exceeds locally the yield point in the direction of the easiest slip plane. It should be noted, however, that the macroscopic $\tau(t)$ can then be purely elastic.

The fatigue stress $\tau(t)$ in (9) is usually understood as a shear stress amplitude function:

$$
\tau(t)=\tau_{\mathrm{a}}^{t}=\left|\tau_{\mathrm{ns}}(t)-\tau_{\mathrm{ns}, \mathrm{m}}\right|
$$

where:

$$
\begin{aligned}
\tau_{\mathrm{ns}}(t) & =\left.\tau(\varphi, \theta, \chi, t)\right|_{\Delta, \chi=\text { const }} \text { is a shear stress on plane } \Delta, \\
\Delta & =\Delta(\varphi, \theta) \text { is a material plane (see Fig. 5), }
\end{aligned}
$$

and

$$
\tau_{\mathrm{ns}, \mathrm{m}} \text { is a mean value of shear stress in that plane. }
$$

Methods of determining the mean value of stress acting in a material plane can be found in Ref. [34]. Hence to find $\tau_{\mathrm{DV}}$ all the material planes (all possible $\varphi$ and $\theta$ ) should be searched out. 


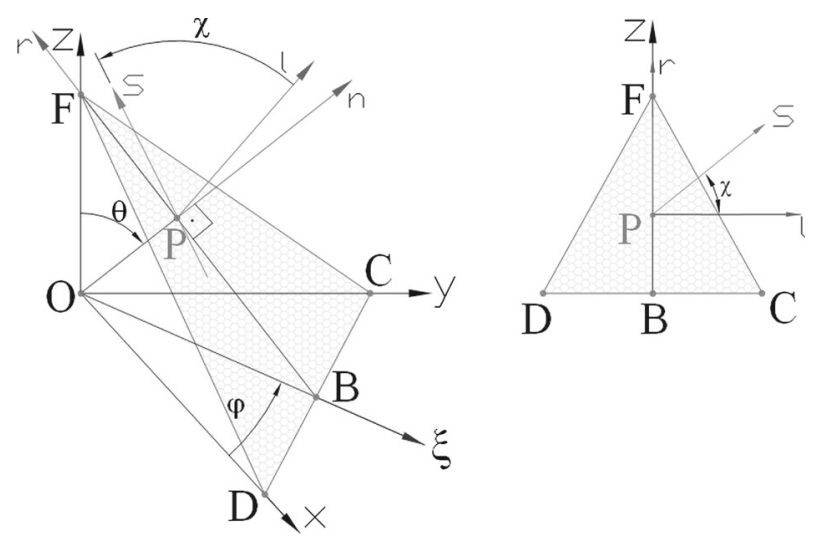

Fig. 5 Graphic representation of orientation of material plane $\Delta$ (CDF) crossing point $\mathrm{O}$ (points $\mathrm{O}$ and $\mathrm{P}$ overlap); orientation is defined by two angles: $\Delta(\varphi, \theta)$ and direction of vector $\mathbf{s}$ in plane $\Delta$ is defined by angle $\mathrm{X}$

\subsection{2 $\mathrm{DV}_{2}$ criterion}

Sometimes the amplitude of stresses is difficult to define. Then, it is reasonable to use $\tau(t)=\tau_{\max }(t)$ in the Tresca-Guest form [18]:

$$
\tau(t)=\tau_{\mathrm{TG}}(t)=\frac{\sigma_{\mathrm{I}}(t)-\sigma_{\mathrm{III}}(t)}{2}
$$

where $\sigma_{\mathrm{I}}, \sigma_{\mathrm{II}}, \sigma_{\mathrm{III}}$ are algebraically ordered principal stresses.

This form can be easily implemented into ANSYS ${ }^{\circledR}$, which may be useful in investigations of large 3D objects or analysis of components in which it is difficult to clearly identify the amplitude and mid-value of shear stress. Criterion $\mathrm{DV}_{2}$ gives more conservative results than $\mathrm{DV}_{1}$ hypothesis, however, one should remember that the method based on the critical plane interpretation is more accurate (better agrees with experiments $[18,30])$.

\subsubsection{Modified Dang Van's criterion ( $D V_{\text {mod }}$ )}

In the original DV model $\left(\mathrm{DV}_{1}\right)[5,33]$ compressive stresses have profitable influence on fatigue effort. It can be observed in reduction of equivalent DV stress $\tau_{\mathrm{DV}}$ for machine elements working in large compression conditions. Such a problem is very important for parts made of hard materials in which constant $a_{\mathrm{DV}}$ achieve larger values. Because of this, the DV model has recently been criticized [11,17,26-28]. One of the proposed modifications of the DV's criterion is to neglect the hydrostatic stress influence by adopting coefficient $a_{\mathrm{DV}}=0$ for negative values of $\sigma_{\mathrm{H}}$ (Fig. 6):

$$
\tau_{\mathrm{DV} \bmod }^{\mathrm{MAX}}=\max _{t}\left\{\begin{array}{lll}
{\left[\tau(t)+a_{\mathrm{DV}} \cdot \sigma_{\mathrm{H}}(t)\right]} & \text { for } & \sigma_{\mathrm{H}} \geq 0 \\
\tau(t) & \text { for } & \sigma_{\mathrm{H}}<0
\end{array}\right\} \leq t_{-1}
$$

\subsection{4 $D V_{2 m o d}$ criterion}

In the $\mathrm{DV}_{2 \text { mod }}$ criterion proposed by the present author shear stress is used in the Tresca-Guest form (13). It is also assumed that compressive stress has no positive effect on fatigue strength (coefficient $a_{\mathrm{DV}}=0$ for negative values of $\sigma_{\mathrm{H}}$ is assumed, see Eq. (14)).

\subsection{Papadopoulos criteria}

\subsubsection{Papadopoulos $P_{1}$ criterion}

In both presented Papadopoulos's criteria the hydrostatic stresses $\sigma_{\mathrm{H}}$ are represented by their maximal values $\sigma_{\mathrm{H}, \max }$, similarly to the Crossland hypothesis. On the other hand, in both Papadopoulos criteria, the first 


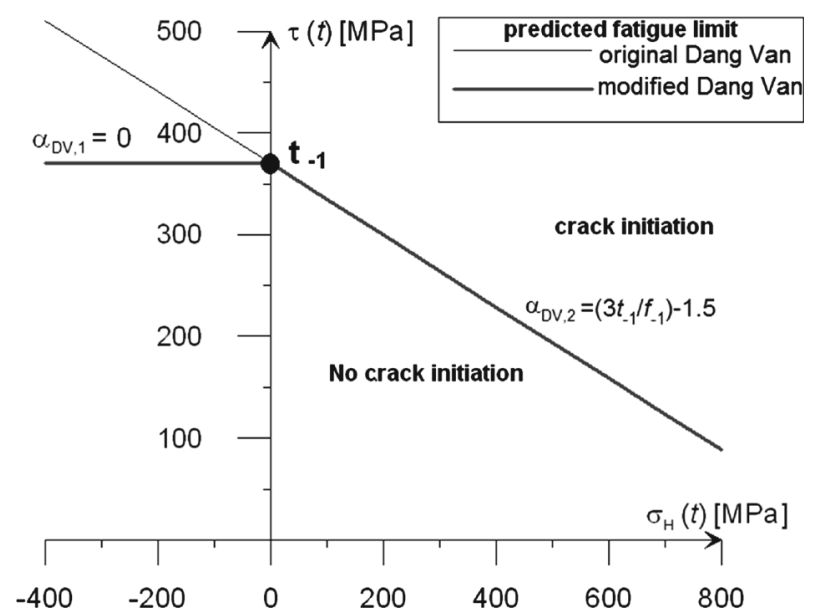

Fig. 6 Modification of Dang Van's criterion (DVmod): neglecting compressive effects in DV formula, (example for steel 30CrNiMo8)

component of the fatigue effort measure is associated with the amplitude $\tau_{\mathrm{a}}$ of resolved shear stress specified for fixed material plane $\Delta$ (determined by $\varphi$ and $\theta$-Fig. 5). For determined material plane $\Delta(\varphi, \theta)$ the amplitude of resolved shear stress $\tau_{\mathrm{a}}$ is a function of $\chi$ :

$$
\tau_{\mathrm{a}}(\varphi, \theta, \chi)=0.5\left[\max _{t \in T} \tau(\varphi, \theta, \chi, t)-\min _{t \in T} \tau(\varphi, \theta, \chi, t)\right]
$$

where $T$ is a close time period considered.

Angle $\chi$ describes the direction of the scalar value of the resolved shear stress $\tau=\boldsymbol{n} \cdot \boldsymbol{\sigma} \cdot \boldsymbol{s}$ on plane $\Delta$, where $\boldsymbol{n}$ and $\boldsymbol{s}$ are vectors defined in Fig. 5 and $\boldsymbol{\sigma}$ is a stress tensor in point $\mathrm{P}$.

In the first version of Papadopoulos's hypothesis [9] proposed for hard materials $\left(0.577<t_{-1} / f_{-1}<0.8\right)$, the following volumetric root-mean-square of resolved shear stress amplitude $<T_{\mathrm{a}}>$ is used:

$$
\begin{aligned}
\tau_{\mathrm{P} 1}^{\mathrm{MAX}} & =\sqrt{\left(\left\langle T_{\mathrm{a}}\right\rangle\right)^{2}}+a_{\mathrm{C}} \cdot \sigma_{\mathrm{H}, \max } \leq t_{-1} \\
\sqrt{\left(\left\langle T_{\mathrm{a}}\right\rangle\right)^{2}} & =\sqrt{\frac{5}{8 \pi^{2}} \int_{\varphi=0}^{2 \pi} \int_{\theta=0}^{\pi} \int_{\chi=0}^{2 \pi} \tau_{\mathrm{a}}^{2}(\varphi, \theta, \chi) \mathrm{d} \chi \cdot \sin \theta \mathrm{d} \theta \mathrm{d} \varphi}
\end{aligned}
$$

where $a_{\mathrm{C}}$ and $\sigma_{\mathrm{H}, \max }$ are defined by expressions $(2,3)$.

This Papadopoulos criterion is based on the average value of plastic strains accumulated in all the flowing crystals in the representative volume element (RVE). RVE is the smallest part of material which can be considered as homogeneous. This value of accumulated plastic strain along the slip direction in an easy-glide plane in a high-cycle regime is, according to $\mathrm{P}_{1}$, almost proportional to the resolved shear stress amplitude (17). Additionally, this measure is independent of the mean resolved shear stress.

For out-of-phase torsion and bending equation (17) takes the following simple form [9]:

$$
\sqrt{\left(\left\langle T_{\mathrm{a}}\right\rangle\right)^{2}}=\sqrt{\frac{\sigma_{x, \mathrm{a}}^{2}}{3}+\tau_{x y, \mathrm{a}}^{2}}
$$

and

$$
\sigma_{\mathrm{H}, \max }=\left(\sigma_{x, \mathrm{a}}+\sigma_{x, \mathrm{~m}}\right) / 3
$$

where $\sigma_{x, \mathrm{a}}, \sigma_{x, \mathrm{~m}}$ is an amplitude and mean value of normal stress by bending, respectively, and $\tau_{x y, \mathrm{a}}$ is an amplitude of the shear stress of torsion. The characteristic feature of the $\mathrm{P}_{1}$ hypothesis is that the phase difference is not taken into account in the above formulas. Because of this, in the criterion $\mathrm{P}_{1}$, based on integral approach, the shift in phase between stresses does not have any influence on the fatigue strength. This is why $\mathrm{P}_{1}$ criterion is criticized [35]. 


\subsubsection{Papadopoulos $P_{2}$ criterion}

The second MHCF model proposed by Papadopoulos in 2001 [6] for analysis of structures made of ferritic steels takes into account generalized shear stress amplitude $T_{\mathrm{a}}$ and the maximal hydrostatic stress:

$$
\tau_{\mathrm{P} 2}^{\mathrm{MAX}}=\max _{\varphi, \theta}\left(T_{\mathrm{a}}\right)+a_{\mathrm{P} 2} \cdot \sigma_{\mathrm{H}, \max } \leq t_{-1}
$$

where

$$
a_{\mathrm{P} 2}= \begin{cases}0 & \text { for } 3 t_{-1} / f_{-1} \leq 1.5 \\ \left(\frac{3 t_{-1}}{f_{-1}}-1.5\right) & \text { for } 3 t_{-1} / f_{-1}>1.5\end{cases}
$$

which is equal to $a_{\mathrm{DV}}$ [see (11)].

The coefficients in formula $\mathrm{P}_{2}$ (fatigue limit $t_{-1}$ and $a_{\mathrm{P} 2}$ ) are designated using the fatigue limits for fully reversed bending $f_{-1}$ and fully reversed torsion $t_{-1}$ which follow from typical fatigue experiments. However, both parameters can also be calculated using the other two fatigue limits, i.e. a tension-compression and a pulsating tension [6]. It should be noted, that this model takes into account shift in phase between stresses. The introduced quantity denoted as $T_{\mathrm{a}}(\varphi, \theta)$ is a function of the material plane orientation (angles $\varphi$ and $\theta$-Fig. 5) and can be determined for each plane $\Delta$ using the relationship:

$$
T_{\mathrm{a}}(\varphi, \theta)=\sqrt{\frac{1}{\pi} \int_{\chi=0}^{2 \pi} \tau_{\mathrm{a}}^{2}(\varphi, \theta, \chi) \mathrm{d} \chi}
$$

where $\tau_{\mathrm{a}}$ is the amplitude (15) of the resolved shear stress, acting in $\Delta$ along the direction defined by $\chi$. The $\mathrm{P}_{2}$ criterion requires determination of the critical plane in which $T_{\mathrm{a}}$ achieves their maximal value. This maximal value of generalized shear stress amplitude $T_{\mathrm{a}}$ is inserted to $\mathrm{P}_{2}$ formula. The specific algorithm for both Papadopoulos criteria can be found in [30].

\section{4 Łagoda energy hypothesis (E)}

The criterion formulated by Łagoda and Macha $[8,29]$ takes into account normal $W_{\mathrm{n}}$ and shear $W_{\mathrm{ns}}$ strain energy density parameter in the critical plane:

$$
W_{\mathrm{eqv}}^{\mathrm{MAX}}=\max _{t}\left\{\beta W_{\mathrm{ns}}(t)+\kappa W_{\mathrm{n}}(t)\right\} \leq W_{\mathrm{af}}
$$

The limit $\left(W_{a f}\right.$ ) has been adopted as $W_{a f}=f_{-1}^{2} /(2 E)$, where $E$ is the Young modulus.

The normal and shear strain energy density parameters can be calculated using given below expressions:

$$
\begin{aligned}
W_{n}(t) & =0.5 \sigma_{\mathrm{n}}(t) \cdot\left[\varepsilon_{\mathrm{n}}(t)-\varepsilon_{\mathrm{n}, \mathrm{m}}\right] \cdot \operatorname{sgn}\left[\sigma_{\mathrm{n}}(t),\left(\varepsilon_{\mathrm{n}}(t)-\varepsilon_{\mathrm{n}, \mathrm{m}}\right)\right] \\
W_{\mathrm{ns}}(t) & =0.5 \tau_{\mathrm{ns}}(t) \cdot\left[\varepsilon_{\mathrm{ns}}(t)-\varepsilon_{\mathrm{ns}, \mathrm{m}}\right] \cdot \operatorname{sgn}\left[\tau_{\mathrm{ns}}(t),\left(\varepsilon_{\mathrm{ns}}(t)-\varepsilon_{\mathrm{ns}, \mathrm{m}}\right)\right]
\end{aligned}
$$

where:

$$
\operatorname{sgn}(x ; y)=\frac{\operatorname{sgn}(x)+\operatorname{sgn}(y)}{2}=\left\{\begin{array}{ll}
1 & \text { if } \operatorname{sgn}(x)=\operatorname{sgn}(y)=1 \\
0 & \text { if } \operatorname{sgn}(x)=-\operatorname{sgn}(y) \\
-1 & \text { if } \operatorname{sgn}(x)=\operatorname{sgn}(y)=-1
\end{array} .\right.
$$

The use of the function $\operatorname{sgn}(x ; y)$ allows for distinguish compression and tension effects. The position of the critical plane $\Delta$ (Fig. 5 ) is designated by the maximum value of shear strain energy density parameter $\left(W_{\mathrm{ns}}^{\mathrm{MAX}}\right)(25)$. It is also assumed, that mean strains $\varepsilon_{\mathrm{n}, \mathrm{m}}$ and $\varepsilon_{\mathrm{ns}, \mathrm{m}}$ have no effect on the fatigue strength. $\beta$ and $\kappa$ are material coefficients can be determined using tension-compression tests or pure alternating bending and torsion:

$$
\beta=\frac{k}{1+v}, \quad k=\left(\frac{f_{-1}}{t_{-1}}\right)^{2}, \quad \kappa=\frac{4-k}{1-v}
$$

where $v$ is the Poisson ratio. 
The equivalent strain energy density parameter $W_{\mathrm{eqv}}^{\mathrm{MAX}}$ calculated using the presented hypothesis is expressed in $\mathrm{MJ} / \mathrm{m}^{3}$. The maximal value of this measure can be referenced to the admissible fatigue limit $W_{\text {af }}$ (23). One of the objectives of the presented study was to compare the described criteria for different kinds of loadings. Consequently, the author introduced equivalent fatigue effort $\tau_{\mathrm{E}}$ for energy criterion expressed in MPa:

$$
\tau_{\mathrm{E}}=t_{-1} \sqrt{\frac{W_{\mathrm{eqv}}^{\mathrm{MAX}}}{W_{a f}}}
$$

This measure can be related to the fatigue limit for fully reversed torsion $\left(t_{-1}\right)$ such as in the other presented criteria.

\section{Verification of selected MHCF criteria for 30CrNiMo8 steel}

All the calculations of fatigue effort were performed numerically using the programs made by the author. The numerical step of determining critical plane orientation $\left(\mathrm{DV}, \mathrm{E}_{\mathrm{L}}, \mathrm{P}_{2}\right) \delta_{\Delta}=5^{\circ}$ for each axis was adopted. The same step value $\delta_{\Delta}$ was used in numerical integration procedures $\left(\mathrm{P}_{1}\right.$ and $\left.\mathrm{P}_{2}\right)$. The results obtained by the Crossland criterion are independent of the numerical step because the stress measures in the Crossland formula are the stress invariants.

Generally, multiaxial high-cycle fatigue hypotheses are formulated for specific materials or types of loading. The author did not find in literature any criterion which could be universally accepted. This fact requires verification of selected hypothesis for particular loading and material by making experimental tests or using different criteria and comparing their results. Recently, the hypotheses based on the concept of the critical plane are very popular. They give more accurate results than the hypotheses based on other approaches. On the other hand, the critical plane orientation generally depends on one or more stress tensor components. A disadvantage of the critical plane based criteria is that the critical plane orientation can be changed for different hypotheses.

In the presented study, all analytical computations of fatigue effort were performed for $30 \mathrm{CrNiMo} 8$ steel $\left(\sigma_{\mathrm{u}}\right.$ at least $\left.900 \mathrm{MPa}\right)$. The typical average chemical composition of this steel is given in Table 1 . The fatigue models described in the paper depend on two material parameters: $t_{-1}$ and $f_{-1}$. The values of these fatigue limits (fully reversed torsion and fully reversed bending tests, respectively) are taken from the experimental tests $[36,37]$ and given in Table 1 .

In all the investigated cases, the sinusoidal loadings of constant amplitudes are used. The distributions of normal and shear stresses are calculated using equations:

$$
\tau(t)=\tau_{\mathrm{a}} \cdot \sin (\omega t+\delta), \quad \sigma(t)=\sigma_{\mathrm{m}}+\sigma_{\mathrm{a}} \cdot \sin (\omega t)
$$

where $\tau_{\mathrm{a}}$ and $\sigma_{\mathrm{a}}$ are the amplitudes of shear and normal stress, respectively, and $\sigma_{\mathrm{m}}$ is the mean value of normal stress and $\delta$ is the shift in phase between normal and shear stress.

Verification of the hypotheses presented in this paper is made for different loading conditions, including non-proportional loading similar to the loads in the rolling contact problem (test no. 5 in Table 2). The selection of the tests is made to the evaluate influence of particular effects (which are important in the RCF analysis) in each selected criterion. The author's investigation included a comparison of fatigue effort analytically calculated with different criteria for a simple case of loading such as fully reversed torsion (test no. 1 in Table 2), fully reversed bending (test no. 2 in Table 2), bending plus in-phase and out-of-phase torsion (test no. 3 in Table 2

Table 1 Average composition of 30CrNiMo8 steel applied to crane wheels and material properties (steel 30CrNiMo8) obtained

\begin{tabular}{|c|c|c|c|c|c|c|c|c|}
\hline \multicolumn{9}{|c|}{ Chemical properties of $30 \mathrm{CrNiMo} 8$} \\
\hline Element & $\mathrm{C}$ & Si (MAX) & $\mathrm{Mn}$ & $\mathrm{P}(\mathrm{MAX})$ & $\mathrm{S}(\mathrm{MAX})$ & & Mo & \\
\hline Weight \% & $0.26-0.34$ & 0.40 & $0.5-0.8$ & 0.025 & 0.035 & $1.8-2.2$ & $0.3-0.5$ & $1.8-2.2$ \\
\hline \multicolumn{9}{|c|}{ Material properties of $30 \mathrm{CrNiMo} 8$} \\
\hline Parameter & $f_{-1}$ & $t_{-1}$ & $\sigma_{\mathrm{y}}($ yield limit $)$ & $\sigma_{\mathrm{u}}($ tensile strength) & $E$ & & & \\
\hline Value MPa & 549 & 370 & $\min .900-\max .1050$ & 1250 & $2.17 \times 10^{5}$ & & & \\
\hline
\end{tabular}
from experimental tests [37] 
Table 2 Equivalent fatigue effort referred to fatigue limit $t_{-1}$ (with formula $x_{z}=t_{-1} / \tau_{\text {eqv }}$ ) for simple loading cases, materialsteel $30 \mathrm{CrNiMo} 8 ; \delta$ - shift in phase between normal and shear stresses

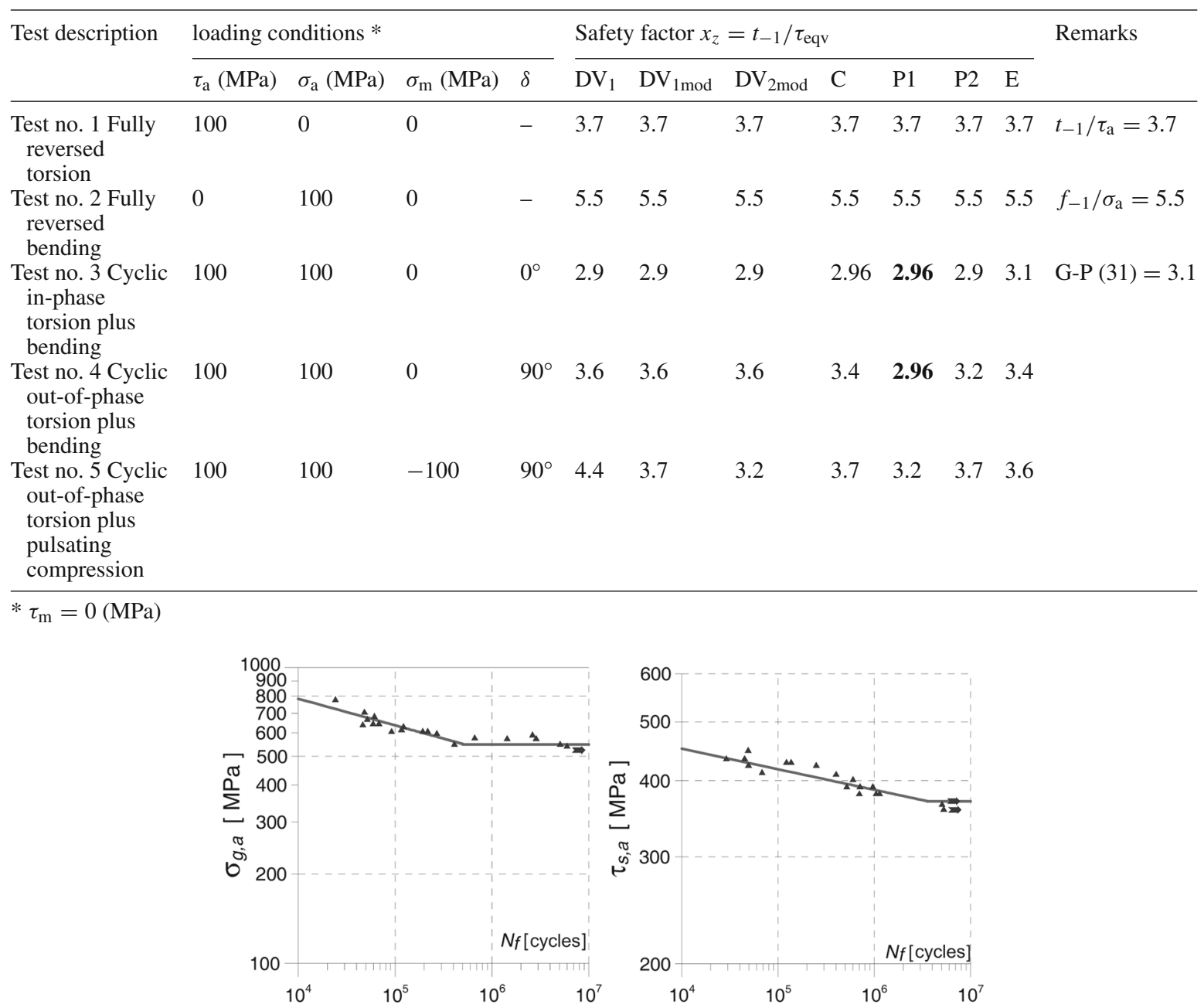

Fig. 7 Fully reversed bending with amplitude $\sigma_{\mathrm{q}, \mathrm{a}}$ (left-hand side) and fully reversed torsion with amplitude $\tau_{\mathrm{s}, \mathrm{a}}$ (right-hand side) experimental data of $30 \mathrm{CrNiMo} 8$ in the $\mathrm{S}-\mathrm{N}$ form

and test no. 4 in Table 2, respectively). Experimental fully reversed bending and fully reversed torsion tests (Fig. 7) were performed by Clemens Sanetra [36] and Alfons Esderts [37] and were carried out on samples of alloy steel $30 \mathrm{CrNiMo8}$. The results in table 2 are given in the form of safety factor $x_{z}$. The value of $x_{z}$ is calculated from the formula:

$$
x_{\mathbf{z}}=\frac{t_{-1}}{\tau_{\text {eqv }}}
$$

where $\tau_{\text {eqv }}$ is the equivalent fatigue stress estimated by particular criteria.

For fully reversed torsion and fully reversed bending all the analysed hypotheses give the same results. Two first sets of the results for fully reversed torsion and bending are in obvious agreement, because the constants of the criteria are derived from these two cases. The criteria in question have also shown convergence for cyclic in-phase bending plus torsion (test no. 3). In addition, the results obtained for the presented loading conditions are compatible with the values set to the corresponding fatigue limits $\left(t_{-1} / \tau_{\mathrm{a}} ; f_{-1} / \sigma_{\mathrm{a}}\right)$. Traditionally, in the case of in-phase bending plus torsion, the value of fatigue effort has been estimated on the basis of the elliptical quadrant criterion formulated by Gough and Pollard [4]:

$$
\left(\frac{\sigma_{\mathrm{a}}}{f_{-1}}\right)^{2}+\left(\frac{\tau_{\mathrm{a}}}{t_{-1}}\right)^{2} \leq 1 .
$$


The comparison of calculations performed for the in-phase (test no. 3) and out-of-phase bending plus torsion test (with shift in phase $\delta=90^{\circ}$ ) (test no. 4) showed that hypothesis $\mathrm{P}_{1}$ based on the average value of stress state does not include the in-phase shift between tangent and normal stresses at the equivalent fatigue effort. This phenomenon can be observed in the comparison of the results obtained for test no. 3 and test no. 4 for $\mathrm{P}_{1}$ criterion (in both cases the safety factor was 2.96; bold letters in Table 2). In other hypotheses, the influence of the in-phase shift between stresses on fatigue effort is approached in different ways. This is indicated by the reduction of equivalent fatigue effort and the increase in safety factor $x_{z}$ (compare the results for test no. 3 and test no. 4) for out-of-phase bending plus torsion tests in comparison with in-phase bending plus torsion test. The largest increase in the safety factor by about $25 \%$ (from 2.9 to 3.6) was observed in the Dang Van's criteria. A much smaller influence of the shift in-phase was observed in the remaining criteria (Crossland $-x_{z}$ is increased by $15 \%$, Papadopolus $\mathrm{P}_{2}-9 \%$ and Lagoda E-9\%). A similar character of loading with the in-phase shift between hydrostatic and shear effects is found in the rolling contact phenomena.

The experimental studies of the influence of the shift in-phase on the fatigue life can be found in Ref. [32,38-43]. The obtained results for in-phase and out-of-phase torsion and bending differ significantly. For brittle (cast iron, sintered steels, cast aluminium) or semiductile materials (cast steels, forged aluminium) the phase shift is advantageous (18G2A, 10HNAP) [42] or has no effect [32,43] for the specimen. In contrast, for ductile materials (structural steels) $[44,45]$ the shift of the phase by $90^{\circ}$ shortens the life limit.

Summarizing, the selection of the MHCF for non-proportional loading should be made on the basis of the material ductility. The second important conclusion is that, criterion $\mathrm{P}_{1}$ is the most conservative. Application of this $\mathrm{P}_{1}$ hypothesis will lead to an increase (which improves the safety) of the equivalent fatigue effort for this kind of loads in relation to the other investigated criteria.

The largest differences are observed in the last 5th case. This example is similar to the rolling contact load. The two characteristic phenomena can be distinguished for such loading condition. The first one is the unfavourable influence of the compressive normal stress on the fatigue life [11,17,26-28]. The second important effect is the shift in phase between pulsative compressive normal stress and fully reversed shear stress. The information on experimental investigations of rolling contact fatigue effects (influence of tri-axial compressive stresses and shift in-phase between normal and shear stresses), which the author has found in the available literature does not seem to be precise enough. The closest to the real loading conditions was experimental fatigue tests for cyclic torsion with compression shift by $90^{\circ}$ performed by Bernasconi, et al. [26]. The samples subjected to such loading conditions caused failure under loading at less than fully reversed torsion limit. Moreover, an increase in the compressive stress results in a decrease in the critical torsion amplitude.

The performed studies for this type of loading have revealed, that the original Dang Van criterion overestimates the effect of hydrostatic stress on decreasing the shear stress amplitude. A detailed study of this problem is described in the Ref. [30]. It results in the underestimation of equivalent fatigue effort and overestimation of the safety factor in comparison with the other criteria. The results obtained using the DV are also in contradiction with the experimental tests [26]. On the other hand, the equivalent fatigue effort for $\mathrm{P}_{2}, \mathrm{C}$, and modified $\mathrm{DV}_{1 \mathrm{mod}}$ is equal to the shear stress amplitude (compare with the fully reversed torsion test- test no. 1). It is associated with the use of $\sigma_{\mathrm{H}, \mathrm{MAX}}$ in these criteria, which in the case of cyclic torsion plus pulsating compression is about 0 . It means that in these criteria the influence of compressive stress on fatigue life is omitted. This is also inconsistent with the experimental tests [26]. The unfavourable influence of out-of-phase torsion-compression loading observed in the experimental test is only included in the criterion $\mathrm{P}_{1}$ based on the integral formulation and the proposed $\mathrm{DV}_{2 \text { mod }}$ hypothesis.

Concluding, the criterion for rolling contact fatigue calculations should be selected on the basis of the influence of the shift in phase between normal (compressive) and shear stresses. Generally, for such application the ductile and high strength alloyed steels are used. For such materials, the introduction of shift in phase between stresses leads to the reduction of fatigue life [44,45]. Moreover, the out-of-phase torsioncompression fatigue tests performed by Bernasconi et al. [26] revealed harmful influence of compression stress and shift in phase between normal and shear stresses on fatigue life. This adverse effect is taken into account only in $\mathrm{P}_{1}$ and $\mathrm{DV}_{2 \mathrm{mod}}$ criteria. Consequently, it is reasonable to use $\mathrm{P}_{1}$ or $\mathrm{DV}_{2 \text { mod }}$ criterion for RCF analysis of the investigated $30 \mathrm{CrNiMo} 8$ steel. However, in order to compare the described MHCF hypotheses for the rolling contact loading condition, the analysis of the crane wheel is made using all the presented criteria. 


\section{FEM modelling of a crane wheel and rail contact}

The 3D numerical analyses of wheel-rail couplings are performed using the FEM. The geometry of the investigated cylindrical crane wheel $\phi 710$ and rail A120 are given in Fig. 8. The research on other wheel-rail coupling is presented in thesis [30]. The chemical composition and material properties of 30CrNiMo8 alloy steel are given in Table 1. In fatigue calculations the maximal admissible design value of the investigated crane wheel loading ( $F=294.3 \mathrm{kN}[46])$ were adopted.

The numerical models and boundary conditions for frictionless and tractive rolling contact are presented in figures (Figs, 9, 10, respectively). Due to a large vertical load and small contact area between the wheel and rail, the stresses in contact zone reach high values, which requires high density finite element grid in the stress concentrations. Also, using a high order contact element with mid-side nodes (CONTA174 in 3D and CONTA172 in 2D analysis) and PLANE82 in 2D and SOLID95 in 3D associated with them are recommended. The corresponding nodes of mesh at rail and wheel should overlap after deformation of the structure, which permits to obtain faster convergence of the numerical solution. Therefore, the element mesh in the presented models was irregular, with a strong concentration of regular hexahedron elements in the contact area.

Using submodelling technique (Fig. 11) the accuracy and efficiency of numerical solution was increased. The Coulomb friction model, closing gaps with AutoCNOF function and the default Augmented Lagrangian
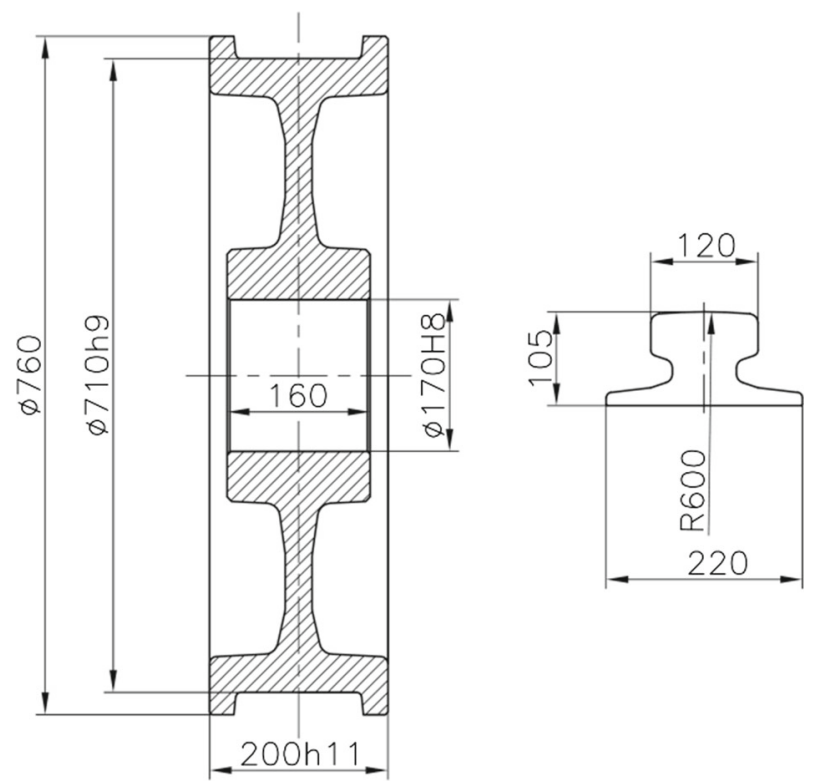

Fig. 8 Cross section and main dimensions of the cylindrical crane wheel $\Phi 710$ and rail A120
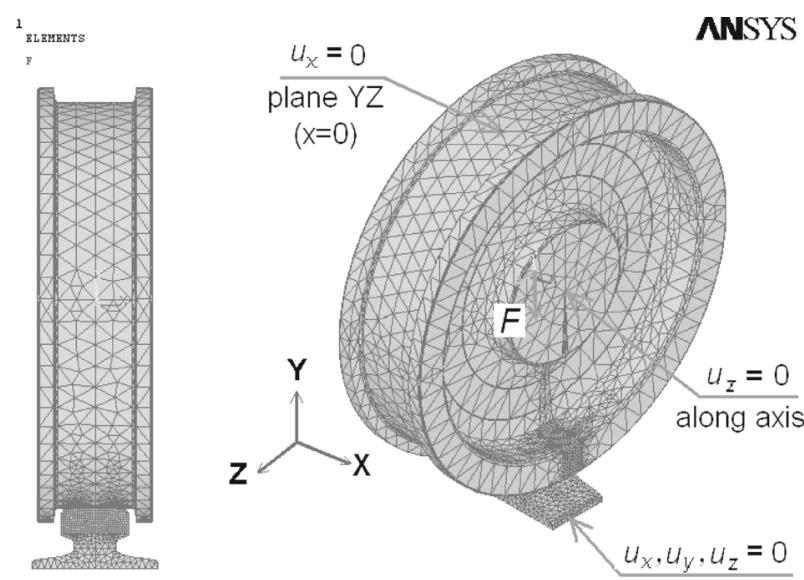

Fig. 9 3D model of cylindrical crane wheel—rail free rolling contact 


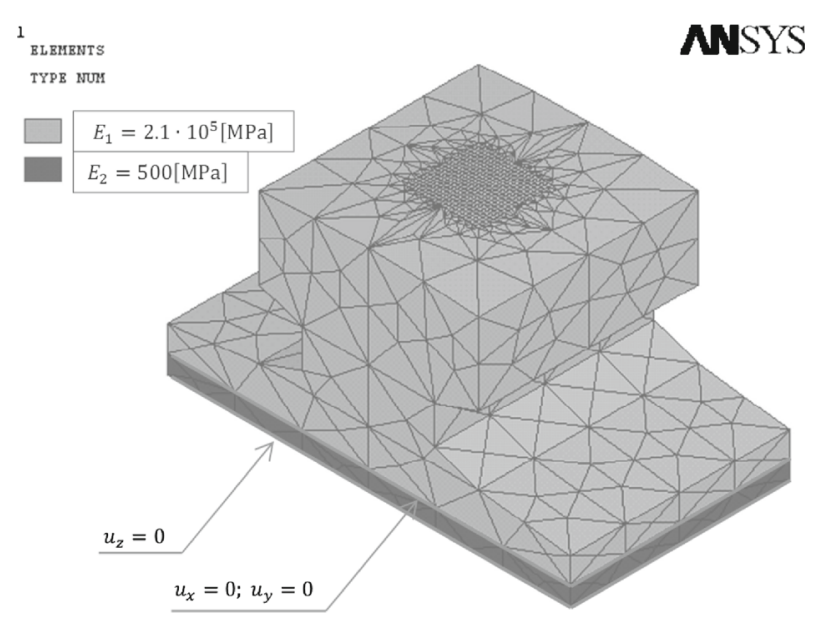

Fig. 10 3D model of rail A120 with divided ground used to calculate driving cylindrical crane wheel—rail tractive rolling contact

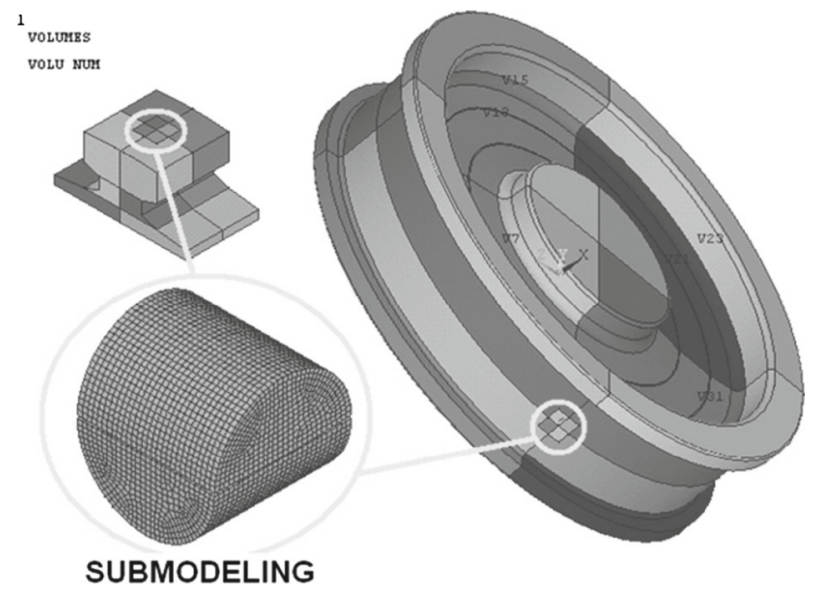

Fig. 11 3D model of cylindrical crane wheel and rail and sub model mesh
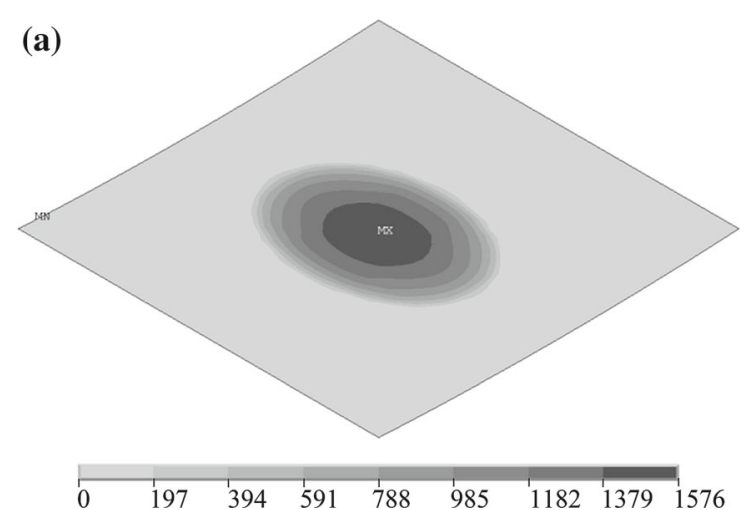
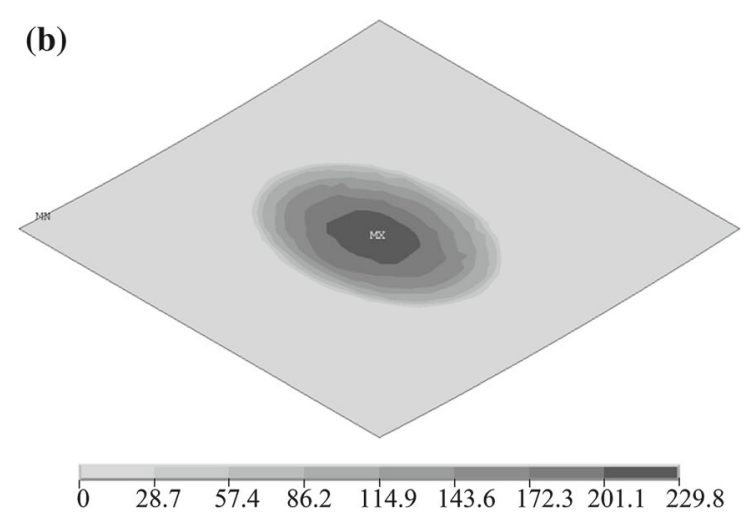

Fig. 12 Contact stress distribution for tractive rolling contact of the investigated cylindrical crane wheel (friction $\mu=0.15$ ) : a contact normal stress distribution, $p_{\circ}=1576 \mathrm{MPa}, \mathbf{b}$ traction contact stress distribution, $p_{\max }=230 \mathrm{MPa}$

method [47] were also applied in the contact solution. Since the value of maximal equivalent stress $\left(\sigma_{\mathrm{vMmax}}=\right.$ $981[\mathrm{MPa}])$ is smaller than the yield limit for $30 \mathrm{CrNiMo} 8$ steel $\left(\sigma_{\mathrm{y}}=1050 \mathrm{MPa}\right)$, only purely elastic model was used in the numerical calculations.

In the case of driving wheels the traction effect between the contacting surfaces should be included in the numerical model. The traction stress distribution for tractive rolling is presented in Fig. 12b. The necessity 


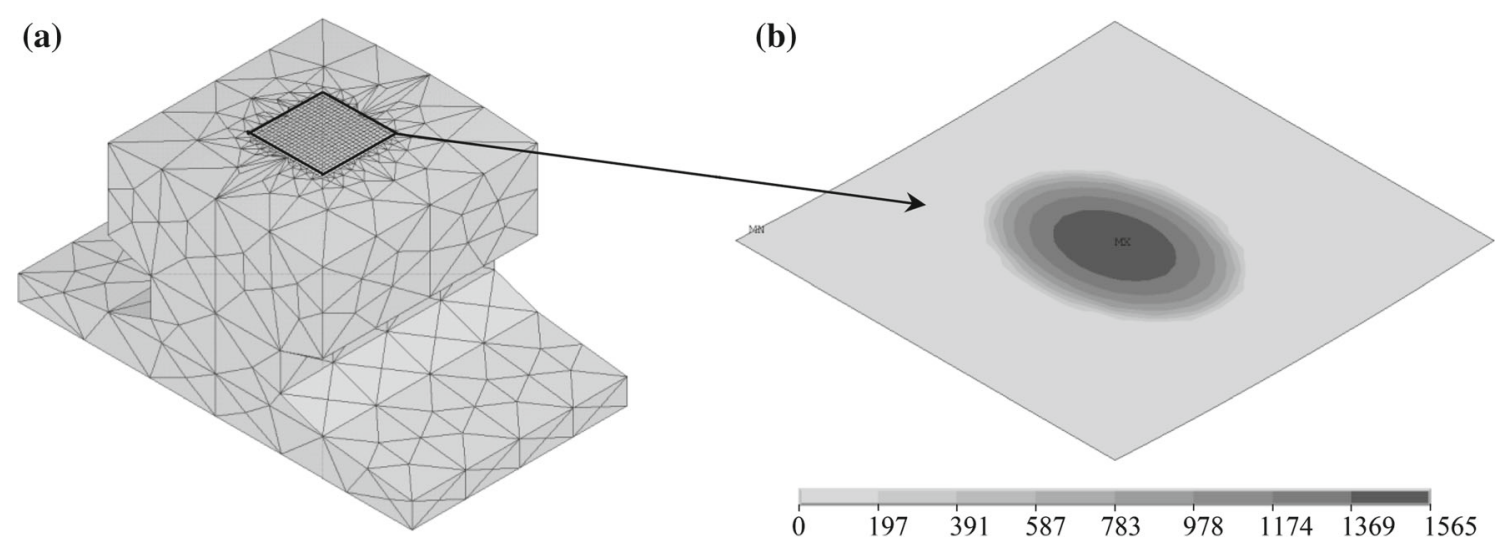

Fig. 13 Contact stress distribution for free rolling contact $(\mu=0.01)$ of the investigated cylindrical crane wheel: a mesh and location of the contact area on the rail A120 (railhead radius $R=600 \mathrm{~mm}$ ), b contact stress distribution, $p_{\circ}=1565 \mathrm{MPa}$

Table 3 Results of numerical calculations for free and tractive rolling contact of cylindrical crane wheel $\phi 710$ and rail A120, $F=294.3 \mathrm{kN}, M=14.4 \mathrm{kNm}$

\begin{tabular}{lll}
\hline & Free rolling & Tractive rolling \\
\hline$p_{\circ}(\mathrm{MPa})$ & 1565 & 1576 \\
$\sigma_{\mathrm{vM}}^{\mathrm{MAX}}(\mathrm{MPa})$ & 981 & 986 \\
$\tau_{y z, \mathrm{MIN}}^{\mathrm{P}-\mathrm{L}}(\mathrm{MPa})$ & -366 & -423 \\
$\tau_{y z, \mathrm{MAX}}^{\mathrm{P}-\mathrm{L}}(\mathrm{MPa})$ & 366 & 296 \\
\hline
\end{tabular}

of including this rolling friction requires a modification of the model proposed for free rolling contact. Its bottom part with small stiffness $\left(E_{2}=500 \mathrm{MPa}\right.$ - details in Fig. 10) allows for including traction effects in the numerical analysis. Torque moment $M=14.4[\mathrm{kNm}]$ driving the wheel is almost equal to its critical value (full sliding; $M_{\text {crit }}=15.7[\mathrm{kNm}]$ for friction coefficient $\mu=0.15$ ). The results presented in the paper are related to the sub model solutions (Fig. 11). The contact stress distribution for tractive and free rolling contact is presented in Figs. 12 and 13, respectively.

\section{Results and discussion}

The railhead radius has a significant effect on the shape of the contact area and contact stresses. Due to different radii of the wheel $\left(R_{\mathrm{W}}=355 \mathrm{~mm}\right)$ and the rail $\left(R_{k}=600 \mathrm{~mm}\right)$ an elliptical contact zone is obtained. The maximal contact stress is $p_{\circ}=1565(\mathrm{MPa})$ (see Table 3 ).

With an increase in friction stress (for high friction coefficient) the equivalent fatigue stress on the wheel tread surface increases (Table 4). It can be explained by a characteristic tension effect which occurs in the tractive rolling. After exceeding a certain value of friction coefficient, surface fatigue can occur. This effect should also be investigated with respect to surface roughness. The maximal equivalent fatigue stresses for the free and tractive rolling contact of the crane wheel and the criteria investigated in Sect. 3 of the paper are presented in Table 4 . The safety factor $x_{z}$ is calculated using formula (30). For all criteria, the alternate torsion fatigue strength $\left(t_{-1}\right)$ is assumed as the fatigue limit.

For the maximal admissible load $F=294.3 \mathrm{kN}$ almost all the multiaxial high-cycle fatigue criteria signalize fatigue failure (the fatigue limit $t_{-1}=370 \mathrm{MPa}$ ). The original DV criterion overestimates the influence of strong hydrostatic stresses on the equivalent shear stress amplitude, which results in a decrease in the estimated fatigue effort in relation to the other criteria (see results in Table 4). The detailed explanation of this problem is discussed in the Ref [30]. Similar critical remarks have been found in several papers [26,27].

The proposed $\mathrm{DV}_{2 \text { mod }}$ (the maximal value of the Tresca-Guest shear stress is used and the impact of compressive hydrostatic stress is disregarded) and $\mathrm{P}_{1}$ hypotheses give the values of the equivalent fatigue effort significantly different from the others. This variant of the DV formula and $\mathrm{P}_{1}$ hypotheses gives the most 
Table 4 The maximal value of the fatigue effort in cylindrical crane wheel in-free and tractive rolling contact for the maximal admissible loading; material $30 \mathrm{CrNiMo8}\left(x_{z}=t_{-1} / \tau_{\text {eqv }}\right)$

\begin{tabular}{|c|c|c|c|c|c|}
\hline \multirow[t]{2}{*}{ Criterion } & \multicolumn{2}{|c|}{ Free rolling* } & \multicolumn{2}{|c|}{ Tractive rolling $* *$} & \multirow[t]{2}{*}{ Remarks } \\
\hline & $\tau_{\text {eqv }}^{\mathrm{MAX}} \mathrm{MPa}$ & $x_{z}$ & $\tau_{\mathrm{eqv}}^{\mathrm{MAX}} \mathrm{MPa}$ & $x_{z}$ & \\
\hline $\mathrm{DV}_{1}$ & 236 & 1.57 & 241 & 1.54 & Overestimated impact of \\
\hline $\mathrm{DV}_{2}$ & 227 & 1.63 & 243 & 1.52 & compressive stress \\
\hline $\mathrm{DV}_{2 \bmod }$ & 480 & 0.77 & 504 & 0.73 & $\begin{array}{l}\text { Overestimated impact of shear } \\
\text { stress }\end{array}$ \\
\hline $\mathrm{DV}_{1 \mathrm{mod}}$ & 364 & 1.02 & 360 & 1.03 & \\
\hline $\mathrm{P}_{1}$ & 471 & 0.79 & 473 & 0.78 & $\begin{array}{l}\text { Neglected shift in phase between normal } \\
\text { and shear effects }\end{array}$ \\
\hline $\mathrm{P}_{2}$ & 373 & 0.99 & 375 & 0.99 & \\
\hline $\mathrm{C}^{-}$ & 386 & 0.96 & 396 & 0.93 & \\
\hline $\mathrm{E}$ & 376 & 0.98 & 393 & 0.94 & \\
\hline
\end{tabular}

* Free rolling: $F=294.3 \mathrm{kN} ; R_{k}=600 \mathrm{~mm}$

** Tractive rolling : $F=294.3 \mathrm{kN} ; M=14.4 \mathrm{kN} \cdot \mathrm{m} ; R_{k}=600 \mathrm{~mm}$

conservative results. The highest values of the fatigue stress in the $\mathrm{DV}_{2 \mathrm{mod}}$ criterion can be explained by using the maximal value of the Tresca-Guest shear stress, which is introduced instead of the amplitude in the critical plane. On the other hand, $\mathrm{P}_{1}$ hypothesis based on the integral approach does not include in-phase shift between stresses. Results obtained using $\mathrm{P}_{1}$ hypothesis agrees with the experimental studies of notched samples made of hard steels (see Sect. 4). In rolling the concentration of stresses is not caused by a notch. Because of this, application of MHCF models based on the integral approach may results in slight overestimation of fatigue effort. However, both $\mathrm{DV}_{2 \bmod }$ and $\mathrm{P}_{1}$ are more conservative and it is suggested to use them if we do not have confirmation of the fatigue effort estimation by experimental results.

The Crossland (C), energy (E), modified Dang Van $\left(\mathrm{DV}_{1 \mathrm{mod}}\right)$ and Papadopoulos $\mathrm{P}_{2}$ hypotheses give almost the same value of safety factor $\mathrm{x}_{z}$ but larger than $\mathrm{P}_{1}$ and $\mathrm{DV}_{2 \text { mod }}$ criteria. One of the reasons is that the $\mathrm{C}, \mathrm{E}$, $\mathrm{DV}_{1 \text { mod }}$ and $\mathrm{P}_{2}$ hypotheses take into account beneficial influence of out-of-phase stresses on fatigue effort. It is in contradiction with the experimental tests for a material with high hardness (see Sect. 4). The results obtained from the above-mentioned criteria $\left(\mathrm{P}_{2}, \mathrm{C}, \mathrm{E}_{\mathrm{L}}\right)$ are in good agreement with the maximal fatigue loading for the investigated crane wheel ( $\mathrm{x}_{\mathrm{z}} \approx 1$ for free rolling contact with the maximum load given by the manufacturer). However, it should be noted that the design maximum loads take into account different magnitudes of loads during the operation of the crane (the calculations are made for the maximal constant loading). In such situation, a crane is designed for variable loading spectrum acting on it during the expected period of exploitation. This has a significant impact on fatigue life and a load histogram should be included in the analysis.

According to Ref. [46] the limit design contact force $F_{\mathrm{Rd} \text {,f }}$ of a wheel and rail for point contact is estimated using formula (32). The minimum contact force $F_{u}(33)$ represents the fatigue strength at 6.4 million cycles under a constant contact force and the probability of survival of $90 \%$.

$$
\begin{aligned}
F_{\mathrm{Rd}, \mathrm{f}} & =\frac{F_{u}}{1.1} \\
F_{u}[k N] & =\left(1.6 f_{y}\right)^{3}\left(\frac{\pi}{1.5}\right)^{3}\left[\frac{3\left(1-v^{2}\right)}{E\left(\frac{2}{D_{W}}+\frac{1}{R_{k}}\right)}\right]^{2}
\end{aligned}
$$

where: $f_{y}$ —is the yield limit (Table 5), $D_{w}=710 \mathrm{~mm}$-is the wheel diameter, $R_{k}=600 \mathrm{~mm}$-is the radius of the rail surface.

The yield limit $\sigma_{\mathrm{y}}$ has a strong impact on $F_{u}(33)$. For the maximal $\sigma_{\mathrm{y}}$ the limit design contact force $F_{\mathrm{Rd}, \mathrm{f}}$ is close to the assumed loading $(F=30 T=294.3 \mathrm{kN})$. However, a reduction of $\sigma_{\mathrm{y}}$ by $10 \%$ results in a reduction of $F_{\mathrm{Rd}, \mathrm{f}}$ by $26 \%$ (Table 5). The real thickness of the wheel rim is about $40 \mathrm{~mm}$, so the yield limit $\sigma_{\mathrm{y}}$ is above $900 \mathrm{MPa}$. Comparing the results obtained for $F=294.3 \mathrm{kN}$ with the limit design forces presented in the table it seems that the results obtained with $\mathrm{P}_{2}, \mathrm{C}, \mathrm{E}, \mathrm{DV}_{1 \mathrm{mod}}$ criteria are underestimated.

The maximal constant loading was also assessed by the author using $\mathrm{P}_{1}$ criterion which is based on integral formulation. The obtained load capacity $F_{P 1 M A X}=266 \mathrm{kN}$ using $\mathrm{P}_{1}$ hypothesis is in good agreement 
Table 5 Minimum contact force $F_{u}$ and limit design contact force $F_{\mathrm{Rd}, \mathrm{f}}$ for investigated wheel and rail (point contact)

\begin{tabular}{llll}
\hline Flat product thickness & $\sigma_{\mathrm{y}}$ (yield limit) & $F_{u}(\mathrm{kN})$ & $F_{\mathrm{Rd}, \mathrm{f}}(\mathrm{kN})$ \\
\hline to $8 \mathrm{~mm}$ & $>1050$ & 343 & 312 \\
$8-20 \mathrm{~mm}$ & 1000 & 296 & 269 \\
& 950 & 254 & 231 \\
$20-60 \mathrm{~mm}$ & $>900$ & 216 & 196 \\
\hline
\end{tabular}

with the values $F_{u}$ and $F_{\mathrm{Rd} \text {,f }}(32)$ for $\sigma_{y}=950-1000 \mathrm{MPa}$. It should be noted that the Papadopoulos $\mathrm{P}_{1}$ hypothesis is also implemented in the analysis of the fatigue load limits of the ball and roller bearings [2,3]. The obtained results for such rolling bearings are in good agreement with the fatigue load limits given by the manufacturer. The above conclusions together with verification of different criteria for out-of-phase loading permit to conclude that $\mathrm{P}_{1}$ and proposed $\mathrm{DV}_{2 \mathrm{mod}}$ criteria (or other criteria based on integral formulation) are the most suitable for rolling contact fatigue analysis.

\section{Conclusions}

In this paper, a detailed analysis of free and tractive RCF of a cylindrical crane wheel using MHCF hypotheses is investigated. The orientations of the critical planes and location of the dangerous points in which subsurface cracks may initiate have been determined and discussed.

It is observed that not all MHCF hypotheses are suitable for the application in RCF. In the original Dang Van formula, which is often proposed for rolling contact fatigue analysis, the shear stress amplitude is decreased by large compressive stress. Therefore, application of the original Dang Van formula for assessment of rolling contact fatigue may result in significant underestimation of the fatigue effort.

The criteria based on energy formulation, stress invariants or critical plane $\left(\mathrm{P}_{2}, \mathrm{C}, \mathrm{E}_{\mathrm{L}}\right)$ assumes profitable in-phase shift between stresses. This assumption is in contradiction with results of experimental tests for hard materials.

On the other hand, results obtained using the hypotheses based on the integral formulation $\left(\mathrm{P}_{1}\right)$ are in good agreement with the experimental tests for notched samples made of hard materials. Moreover, the maximal loading obtained with the use of $\mathrm{P}_{1}$ is corresponding with the estimated maximal constant loading using Standard [47] for the investigated crane wheel. However, the subsurface stress state under the wheel tread surface differs from the state in test specimens. This is why, neglecting shift in phase between stresses can lead to excessive increase (which improves safety) of the equivalent fatigue stress value in RCF for particular materials. This phenomenon requires a more detailed experimental study of samples working in the rolling contact condition. Similar results are obtained using the proposed $\mathrm{DV}_{2 \mathrm{mod}}$ criterion. The advantage of this criterion is that it does not require time-consuming integral calculations and uses a simple form of TrescaGuest shear stress.

Summarizing the analysis of fatigue life, calculation of load capacity or estimation of the maximal fatigue load of machine elements made of hard materials and working in rolling contact condition should be investigated using multiaxial high-cycle fatigue hypotheses based on the integral approach.

On the basis of the above conclusions it can be stated that the design of the investigated wheel is not conservative for $F=294.3 \mathrm{kN}$. The maximal admissible load for the investigated crane wheel, calculated using $\mathrm{P}_{1}$ criterion with safety factor $x_{z}=1$, is $F=266 \mathrm{kN}$.

Open Access This article is distributed under the terms of the Creative Commons Attribution 4.0 International License (http:// creativecommons.org/licenses/by/4.0/), which permits unrestricted use, distribution, and reproduction in any medium, provided you give appropriate credit to the original author(s) and the source, provide a link to the Creative Commons license, and indicate if changes were made.

\section{References}

1. DIN 536-1 - Crane Rails Hot Rolled Flat Bottom Crane Rails (Type a) Dimensions, Section Parameters and Steel Grades (1991) 
2. Romanowicz, P.: Application of selected multiaxial high-cycle fatigue criteria to rolling contact problems. Key Eng. Mater. 542, 157-170 (2013)

3. Romanowicz, P., Szybiński, B.: Estimation of maximum fatigue loads and bearing life in ball bearings using multi-axial high-cycle fatigue criterion. Appl. Mech. Mater. 621, 95-100 (2014)

4. Weber, B.: Fatigue multiaxiale des structures industrielles sous chargement quelconque [En ligne]Thèse: Institut National des Sciences Appliquées de Lyon (1999)

5. Van Dang, K., Maitournam, M.H.: On some recent trends in modelling of contact fatigue and wear in rail. Wear 253, 219-227 (2002)

6. Papadopoulos, I.V.: Long life fatigue under multiaxial loading. Int. J. Fatigue 23, 839-849 (2001)

7. Crossland, B.: Effect of large hydrostatic pressures on the torsional fatigue strength of an alloy steel. In: Proceedings, International Conference on Fatigue of Metals. Institution of Mechanical Engineers, London, pp. 138-149 (1956)

8. Lagoda, T.: Fatigue life of welded joints according to energy criteria in the critical plane. Strength Mater. 38, 417-422 (2006)

9. Papadopoulos, I.V., Davoli, P., Gorla, C., Filippini, M., Bernasconi, A.: A comparative study of multiaxial high-cycle fatigue criteria for metals. Int. J. Fatigue 19, 219-235 (1997)

10. Ekberg, A., Kabo, E.: Fatigue of railway wheels and rails under rolling contact and thermal loading-an overview. Wear 258, 1288-1300 (2005)

11. Ciavarella, M., Monno, F.: A comparison of multiaxial fatigue criteria as applied to rolling contact fatigue. Tribol. Int. 43, 2139-2144 (2010)

12. Brunel, J.-F., Charkaluk, E., Dufrenoy, P., Demilly, F.: Rolling contact fatigue of railways wheels: influence of steel grade and sliding conditions. Procedia Eng. 2, 2161-2169 (2010)

13. Kim, T.W., Cho, Y.J., An, D.M., Lee, H.W.: The fatigue crack initiation life prediction based on several high-cycle fatigue criteria under spherical rolling contact. Tribol. Trans. 46(1), 76-82 (2003)

14. Liu, Y., Stratman, B., Mahadevan, S.: Fatigue crack initiation life prediction of railroad wheels. Int. J. Fatigue 28, 747-756 (2006)

15. Liu, Y., Limin, L., Stratman, B., Mahadevan, S.: Multiaxial fatigue reliability analysis of railroad wheels. Reliab. Eng. Syst. Saf. 93, 456-467 (2008)

16. Liu, Y., Liming, L., Mahadevan, S.: Analysis of subsurface crack propagation under rolling contact loading in railroad wheels using FEM. Eng. Fract. Mech. 74, 2659-2674 (2007)

17. Conradoa, E., Gorlaa, C.: Contact fatigue limits of gears, railway wheels and rails determined by means of multiaxial fatigue criteria. Procedia Eng. 10, 965-970 (2011)

18. Ekberg, A.: Rolling contact fatigue of railway wheels - a parametric study. Wear 211, 280-288 (1997)

19. Bernasconi, A., Davoli, P., Filippini, M., Foletti, S.: An integrated approach to rolling contact sub-surface fatigue assessment of railway wheels. Wear 258, 973-980 (2005)

20. Van Dang, K., Maitournam, M.H.: Rolling contact in railways: modelling, simulation and damage prediction. Fatigue Fract. Eng. Mater. Struct. 26, 939-948 (2003)

21. Sandstrom, J.: Evaluation of Dang Van stress in Hertzian rolling contact. Fatigue Fract. Eng. Mater. Struct. 35, 1088-1094 (2012)

22. Ekberg, A., Kabo, E., Andersson, H.: An engineering model for prediction of rolling contact fatigue of railway wheels. Fatigue Fract. Eng. Mater. Struct. 25(10), 899-909 (2002)

23. Cerullo, M.: Application of Dang Van criterion to rolling contact fatigue in wind turbine roller bearings. In: 13th International Conference on Fracture, June 16-21, 2013, Beijing, China (2013)

24. Houpert, L., Chevalier, F.: Rolling bearing stress based life-part I: calculation model. J. Tribol. (2012). doi:10.1115/1.4006135

25. Ciavarella, M., Monno, F., Demelio, G.: On the Dang Van fatigue limit in rolling contact fatigue. Int. J. Fatigue 28, 852-863 (2006)

26. Bernasconi, A., Filippini, M., Foletti, S., Vaudo, D.: Multiaxial fatigue of a railway steel under non-proportional loading. Int. J. Fatigue 28, 663-672 (2006)

27. Desimone, H., Bernasconi, A., Beretta, S.: On the application of Dang Van criterion to rolling contact fatigue. Wear 260, 567-572 (2006)

28. Foletti, S., Beretta, S., Tarantino, M.G.: Multiaxial fatigue criteria versus experiments for small crack under rolling contact fatigue. Int. J. Fatigue 58, 181-192 (2014)

29. Kluger, K., Łagoda, T.: Fatigue lifetime under uniaxial random loading with different mean values according to some selected models. Mater. Des. 28, 2604-2610 (2007)

30. Romanowicz, P.: Fatigue analysis of selected machine elements working at rolling contact condition. Ph.D. Thesis, Cracow University of Technology (2010)

31. Johnson, K.L.: Contact Mechanics. Cambridge University Press, Cambridge (1985)

32. Sonsino, C.M.: Influence of material's ductility and local deformation mode on multiaxial fatigue response. Int. J. Fatigue 33, 930-947 (2011)

33. Van Dang, K., Griveau, B., Message, O.: On a new multiaxial fatigue limit criterion: theory and application. In: Brown, M.W., Miller, K.J. (eds.) Biaxial and Multiaxial Fatigue, EGF 3, pp. 479-496. Mechanical Engineering Publications, London (1989)

34. Bernasconi, A., Papadopoulos, I.V.: Efficiency of algorithms for shear stress amplitude calculation in critical plane class fatigue criteria. Comput. Mater. Sci. 34, 355-368 (2005)

35. You, Bong-Ryul, Lee, Soon-Bok: A critical review on multiaxial fatigue assessments of metals. Int. J. Fatigue 18, 235-244 (1996)

36. Sanetra, C.: Untersuchungen zum Festigkeitsverhalten bei mehrachsiger Randombeanspruchung unter Biegung und Torsion. Dissertation, Technische Universitat Clausthal (1991)

37. Esderts, A.: Betriesfestigkeit bei mehrachsiger Biege- und Torsionbeanspruchung. Dissertation, Technische Universitat Clausthal (1995)

38. Nishihara, T., Kawamoto, M.: The strength of metals under combined alternating bending and torsion with phase difference. Mem. Coll. Eng. Kyoto Imp. Univ. 11, 85-112 (1945) 
39. Heidenreich, R., Zenner, H., Richter, I.: Dauerschwingfestigkeit bei mehrachsiger Beanspruchung. Forschungshefte FKM, Heft 105 (1983)

40. Lempp, W.: Festigeitsverhalten von Stählen bei mehrachsiger Dauerschwingbeanspruchung durch Normalspannungen mit überlagerten phasengleichen und phasenverschobenen Schubspannungen. Dissertation, University of Stuttgart (1997)

41. Froustey, C., Lasserre, S.: Multiaxial fatigue endurance of 30NCD16 steel. Int. J. Fatigue 11, 169-175 (1989)

42. Marciniak, Z., Rozumek, D., Macha, E.: Fatigue lives of 18G2A and 10HNAP steels under variable amplitude and random non-proportional bending with torsion loading. Int. J. Fatigue 30, 800-813 (2008)

43. Skibicki, D.: A fatigue failure criterion for multiaxial loading with phase shift and mean value. J. Theor. Appl. Mech. 42 , 295-314 (2004)

44. Skibicki, D., Socie, D.: Multiaxial fatigue damage models. J. Eng. Mater. Technol. Trans. ASME 109, $293-298$ (1987)

45. Socie, D.F.: Multiaxial fatigue damage models. J. Eng. Mater. Technol. Trans. ASME 109, 293-298 (1987)

46. $\mathrm{prCEN} / \mathrm{TS}$ 13001-3-3 Cranes - General design - Part 3-3: Limit states and proof of competence of wheel/rail contacts (2009)

47. Release 11.0 Documentation for ANSYS (2007) 